\title{
Correction to: Mental health status among family members of health care workers in Ningbo, China, during the coronavirus disease 2019 (COVID-19) outbreak: a cross- sectional study
}

Yuchen Ying ${ }^{1,2,3+}$, Liemin Ruan ${ }^{3+}$, Fanqian Kong ${ }^{4}$, Binbin Zhu ${ }^{5}$, Yunxin $\mathrm{Ji}^{3}$ and Zhongze Lou $^{3^{*}}$

Correction to: BMC Psychiatry 20, 379 (2020)

https://doi.org/10.1186/s12888-020-02784-w

Following the publication of the original article [1], the authors identified a mismatch between the assigned affiliations and numbering. The correct assigned affiliations and numbering are given below.

Yuchen Ying1,2,3+, Liemin Ruan3†, Fanqian Kong4, Binbin Zhu5, Yunxin Ji3 and Zhongze Lou3*

2. Ningbo College of Health Sciences, Ningbo, Zhejiang 315,010, P.R. China.

3. Department of Psychosomatic Medicine, Ningbo First Hospital, Ningbo Hospital of Zhejiang University, 59 Liuting Street, Haishu District, Ningbo, Zhejiang 315, 211, P.R. China.

The author group has been updated above and the original article [1] has been corrected.

\section{Author details}

${ }^{1}$ School of Medicine, Ningbo University, Ningbo, Zhejiang 315211, P.R. China.

${ }^{2}$ Ningbo College of Health Sciences, Ningbo, Zhejiang 315010, P.R. China.

${ }^{3}$ Department of Psychosomatic Medicine, Ningbo First Hospital, Ningbo Hospital of Zhejiang University, 59 Liuting Street, Haishu District, Ningbo, Zhejiang 315211, P.R. China. ${ }^{4}$ Department of Medical Record and Statistics, Ningbo Medical Center Lihuili Hospital, Ningbo, Zhejiang 315041, P.R. China.
${ }^{5}$ Department of Anesthesiology, The Affiliated Hospital of Medical School of Ningbo University, Ningbo 315020, P.R. China.

Published online: 25 January 2021

\section{Reference}

1. Ying, et al. Mental health status among family members of health care workers in Ningbo, China, during the coronavirus disease 2019 (COVID-19) outbreak: a cross-sectional study. BMC Psychiatry. 2020;20:379. https://doi. org/10.1186/s12888-020-02784-w.

The original article can be found online at https://doi.org/10.1186/s12888020-02784-w.

*Correspondence: Iorenzo_87@163.com

${ }^{\dagger}$ Yuchen Ying and Liemin Ruan contributed equally to this work.

${ }^{3}$ Department of Psychosomatic Medicine, Ningbo First Hospital, Ningbo

Hospital of Zhejiang University, 59 Liuting Street, Haishu District, Ningbo,

Zhejiang 315211, P.R. China

Full list of author information is available at the end of the article

(c) The Author(s). 2021 Open Access This article is licensed under a Creative Commons Attribution 4.0 International License, which permits use, sharing, adaptation, distribution and reproduction in any medium or format, as long as you give appropriate credit to the original author(s) and the source, provide a link to the Creative Commons licence, and indicate if changes were made. The images or other third party material in this article are included in the article's Creative Commons licence, unless indicated otherwise in a credit line to the material. If material is not included in the article's Creative Commons licence and your intended use is not permitted by statutory regulation or exceeds the permitted use, you will need to obtain permission directly from the copyright holder. To view a copy of this licence, visit http://creativecommons.org/licenses/by/4.0/ The Creative Commons Public Domain Dedication waiver (http://creativecommons.org/publicdomain/zero/1.0/) applies to the data made available in this article, unless otherwise stated in a credit line to the data. 